\title{
Professor Shu-Ting Chang on His 90th Birthday
}

\author{
Solomon P. Wasser \\ Department of Evolutionary and Environmental Biology and Institute of Evolution, Faculty of Natural Sciences, \\ University of Haifa, Mount Carmel, Haifa 31905, Israel; Tel.: +972-4-824-9653; Fax: +972-4-8-288-197, \\ E-mail: spwasser@research.haifa.ac.il
}

On September 30, 2020, Professor Shu-Ting Chang, S-T to many of his friends and acquaintances, editor of the International Journal of Medicinal Mushrooms, celebrated his 90th birthday. We started celebration of the forthcoming jubilee of Professor Shu-Ting Chang in September 2019 during the 10th International Medicinal Mushrooms Conference. The event was preceded by a 1-day symposium dedicated to Professor Chang, who is regarded as the godfather of medicinal mushrooms. Presentations were dedicated to Professor Chang's academic work, including his contribution to the development of culinary-medicinal mushrooms in China, Africa, and South America; a review of his academic career; the master principles of S-T Chang: inheritance and development; his pyramid model for edible mushrooms; S-T Chang's wishes for the development of the mushroom industry; his travels across five continents teaching mushroom biology, and many others. He has spent well over 60 years promoting the cultivation of mushrooms as food and medicine, and has published more than 230 scientific papers and authored 23 books. He was also one of the initiators of the International Journal of Medicinal Mushrooms in 1999, and remains an editor today. Professor Chang is currently 90 but still remains in good health and always has a smile on his face.

Professor Shu-Ting Chang's name occupies a prominent place in the world of mycology because of his outstanding input into the fields of mushroom biology, mushroom cultivation, and medicinal mushrooms. Professor Chang is a world leader in mushroom biology and medicinal mushroom science. Professor Chang is also a great teacher. Many of his students have received both master's and $\mathrm{PhD}$ degrees. He is not only an academic teacher, but also a practical teacher for mushroom growers and farmers around the world, including China and some African and South American countries. Professor Chang is a great scientific organizer. $\mathrm{He}$ is one of the main organizers of all ten International Medicinal Mushroom Conferences.

Professor Chang was born in Yuanping, Shanxi, China, and graduated from the National Taiwan University with a B.S. degree in 1953. He received his M.S. from the University of Wisconsin, in the United States, in 1958. He stayed on at the University of Wisconsin to pursue his PhD, which he received in 1960. After receiving his $\mathrm{PhD}$, he started his professional career at the Chinese University of Hong Kong (CUHK) as an assistant lecturer in biology and worked his way up to Emeritus Professor. Throughout his scientific career, over a span of 50 years, he has been connected to CUHK in one way or another. He also influenced administrative changes in the Department of Biology at CUHK: from 1974 to 1977, as Dean of the Faculty of Science; from 1979 to 1981, as Director of the Office of Student Affairs; from 1983 to 1994, as Chairman of the Department of Biology. From 1975 to 1985 he was the Director of Research Laboratory for Food Protein Production. From 1983 until 1994, he was Director of the Marine Science Laboratory. In 1985, he became the Director of the Institute of Science and Technology, where he remained until 1992. In 1980, he was the Head of the Division of Biology in the Graduate School. From 1983 through 1994, he was Chairman of the Board of Studies in Biology. Professor Chang became Chairman of the Science Center Management Committee, which he served on for three years. In 1991, he worked as Director of the Chinese Medicinal Material Research Center for one year. From 1993 to 1995 he was Chairman of the Science Engineering Complex Management Committee.

In addition, Professor Chang is Honor President of the International Society of Medicinal Mushrooms. He has served as the Vice President of the World Society for Mushroom Biology and Mushroom Products, and was a member of the Executive Committee of International Society for Mushroom Science (ISMS) from 


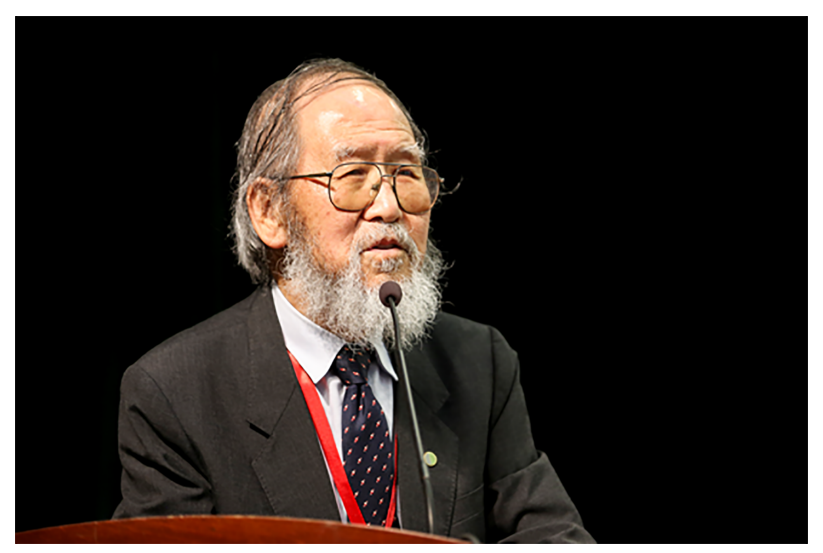

FIG. 1: Professor S-T Chang during the 8th International Medicinal Mushrooms Conference (August 2015, Manizales, Colombia)

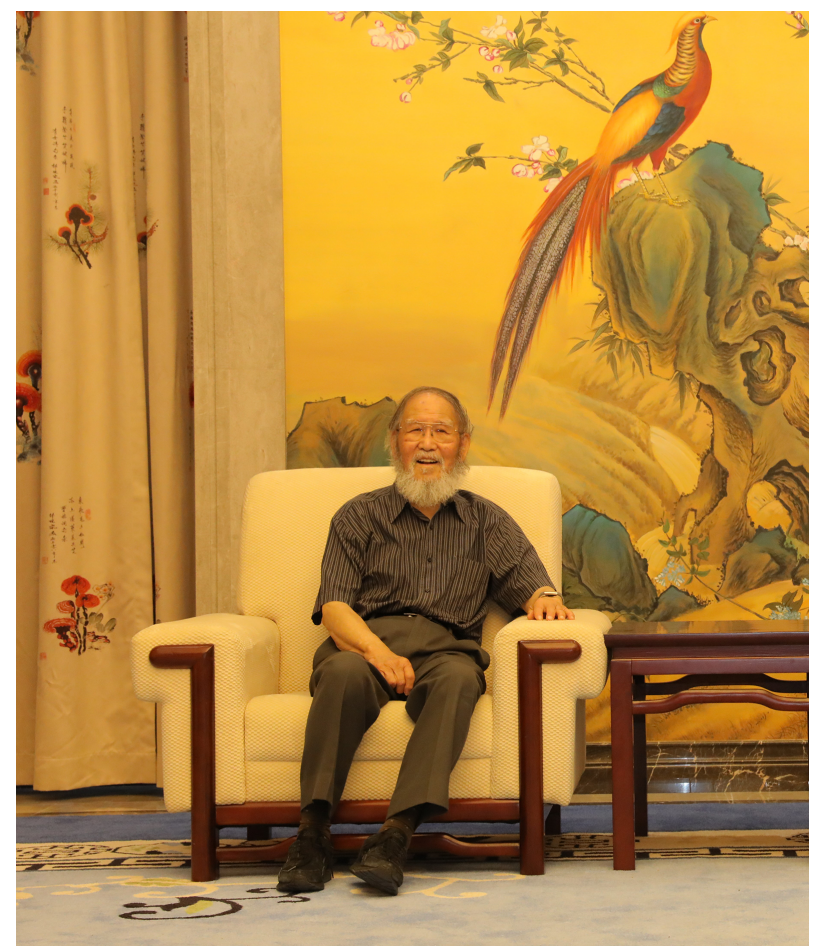

FIG. 2: Professor S-T Chang during the 10th International Medicinal Mushrooms Conference (September 2019, Nantong, China)

1996 to 2004. Professor Chang was also the President of the International Mushroom Society for the Tropics (1981-95), National-Point-of-Contact Representative of Hong Kong for the UNESCO Regional Network of Microbiology in Southeast Asia (1981-93), and Executive Secretary of the Headquarters of the UNESCO Regional Network of Microbiology in Southeast Asia (1984-87). He was elected to the Executive Board of International Union of Microbiological Societies (IUMS) (1990-94) and was a member of the Standing Committee on Membership, Structure and Status of International Council of Scientific Unions (ICSU) (1993-96). 
As an eloquent and prominent speaker, Professor Chang has also been associated with agencies within the UN, e.g., UNESCO, UNDP/UNOPS, UNU, UNIDO, and FAO, as a consultant on mushroom cultivation and mushroom products since 1977. Since 2000, Professor Chang has been invited twice by the Commonwealth Secretariat in London to serve as a consultant on mushroom farming in Namibia. He has also been invited to conduct many training workshops/courses on mushroom biology and mushroom biotechnology all over the five continents, most recently in African and Latin American countries, sponsored by UNDP/UNOS. He has also been invited to serve as scientific advisor and Honorary Professor for over 30 research institutes and universities in China, and has received many awards. The diversity of Chang's research programs, scientific, organizational, and pedagogical activities and his significant achievements in various fields of mycology represent him as a scientist of a wide scope of interests, a brilliant scientific organizer, a world scientific leader of the school of mushroom biology, whose achievements and accomplishments have become incorporated into the world of science.

Since 1960, Professor Chang's main field of research has been mushroom biology, mushroom technology for cultivation, and mushroom biotechnology for tonic and medicinal products. His main philosophy and drive behind this line of research can be summarized as follows. Modern technology for human civilization is expanding every day. However, human beings still face, and will continue to face, three basic problems capable of causing crises: shortage of food, pollution of the environment, and diminishing quality of human health resulting from a continuously increasing world population. Mushrooms (macrofungi) not only can convert huge amounts of lignocellulosic biomass waste into protein-rich food, but can also produce notable nutriceutical/pharmaceutical products that have many health benefits. The most significant aspect of mushroom cultivation is to create pollution free or zero emission environments. In addition, mushroom-based farming and industry could provide employment for youth and women, particularly in rural areas in less developed countries. Mushrooms are relatively fast-growing organisms: some tropical mushrooms can be harvested and consumed within 10 days after spawning. By using different varieties, mushrooms can be cultivated all year round.

Professor Chang's main research areas are

1. The life-cycle of mushrooms using genetic and cytological techniques;

2. Improvement of mushroom strains by genetic manipulation including molecular markers and protoplast fusion techniques;

3. Nutritive values and medicinal effects of mushrooms;

4. Development and improvement of cultivation technology;

5. Development of new concepts of mushroom biology, mushroom science (concerned with mushroom production), and mushroom biotechnology (concerned with mushroom products); and

6. Introduction and development of terms and concepts such as "what is a mushroom?," "mushroom biology," "mushroom nutriceuticals," and the "non-green revolution."

This research has improved the supply of nutritious food for human consumption, the quality of life for humanity, and the condition of polluted environments.

Professor Chang's research has contributed to projects that continue to have an impact at national, regional, and global levels:

1. In 1969, cotton waste from cotton textile industry was used for the first time to grow straw mushrooms (Volvariella volvacea) in Hong Kong.

2. Protoplast techniques were used to breed high-temperature strains of shiitake culinary-medicinal mushroom (Lentinus edodes).

3. The new disciplines of mushroom biology and mushroom biotechnology were established, leading to the First International Conference on Mushroom Biology and Mushroom Products, held at the 
Chinese University of Hong Kong, August 23-26, 1993, and also leading to the formation of the World Society of Mushroom Biology and Mushroom Products (WSMBMP).

4. "Mushroom nutriceuticals" was introduced as a term and concept with Professor J.A. Buswell in 1996.

5. The term "non-green revolution" was applied to mushroom cultivation and mushroom products in 1998, owing to the positive effects of cultivation and development of edible and medicinal mushrooms on equitable economic growth and human welfare. Benefits include use of mushrooms as food, health tonic, medicine, animal feed, and fertilizer; for protecting and regenerating the environment; and for promoting sustainable development and contributing positively to economic and social conditions.

As mentioned previously, Professor Chang is an author or co-author of 23 books. Special attention must be drawn to his latest book with Professor P.G. Miles, published in 2004, entitled Mushrooms: Cultivation, Nutritional Value, Medicinal Effect, and Environmental Impact. This book is an encyclopedic review of mushroom biology including cultivation, nutritional value, medicinal value, and environmental impact, and emphasizes worldwide trends and developments in mushroom biology from an international perspective and is highly recommended for medicinal mycologists, mushroom growers, botanists, plant pathologists, and professionals and scientists in related fields. Chang's book illustrates that mushroom cultivation has and will continue to have a positive global impact on long-term food nutrition, healthcare, environmental conservation, regeneration, and economic and social change. The value of this book cannot be overstated. The book is used extensively in universities, classroom, laboratories, etc., and is useful for beginning students through PhD studies and beyond. To our knowledge, no past or current book comes close to covering all the subjects considered in this volume.

As editor of our special International Journal of Medicinal Mushrooms, he has been a critical and proficient reviewer of several articles, as well as an author himself. During this time, he published several keynote papers in our journal:

- Global impact of edible and medicinal mushrooms on human welfare in the 21st century: nongreen revolution (IJMM 1999;1:1-8)

- World production of cultivated edible and medicinal mushrooms in 1997 with emphasis on Lentinus edodes (Berk.) Sing. in China (IJMM 1999;1:291-300)

- Ganoderma lucidum (Curt.:Fr.) P.Karst. (Aphyllophoromycetidae) - a mushrooming medicinal mushroom (IJMM 2000;2:139-146)

- A 40-year journey through bioconversion of lignocellulosic wastes to mushrooms and dietary supplements (IJMM 2001;3:299-310)

- The world mushroom industry: trends and technological development (IJMM 2006; 8:297-314)

Several papers deserve special mention. In "The need for scientific validation of culinary-medicinal mushroom products" (IJMM 2006;8:187-195), Professor Chang proposed the "G" guidelines for the production of high-quality mushroom products:

1. GLP: Good Laboratory Practice

2. GAP: Good Agriculture Practice

3. GMP: Good Manufacturing Practice

4. GPP: Good Production Practice

5. GCP: Good Clinical Practice

In "Development of the culinary-medicinal mushrooms industry in China: past, present, and future" (IJMM 2006;8:1-17), Professor Chang brought attention to the World Mycological and Mushroom Growers 
Society's achievements in the culinary-medicinal mushroom_industry in China. In 1978, Professor Chang was invited to conduct the first mushroom training workshop in China. At that time, production of cultivated mushrooms in China was only 60,000 tons, and after 25 years, in 2003, China's mushroom production had increased to 9 million tons (approximately $70 \%$ of the world's total production). Now China is the number one mushroom producer in the world, and also the largest consumer and exporter of mushrooms in the world; China produces over $80 \%$ of the world's shiitake culinary-medicinal mushrooms. In this breakthrough paper, Chang elucidated possibilities for future development in the medicinal mushroom industry and also urged Chinese colleagues to pay attention to some unsolved problems in the production of Chinese mushrooms and in cultivation improvement. Finally, in this paper, Chang outlined the following reasons why China has been so successful in the development of its mushroom industry, and how it can serve as an example for what is possible for other, especially developing, countries:

1. Strong leadership and initiatives of central government and local institutions.

2. Many innovations in mushroom cultivation by local governments.

3. Strong scientific support of academic technology by mushroom farmers.

4. The growth of domestic markets as a result of a strong national economy, which has been a key factor in the expansion of China's mushroom cultivation.

Further papers include:

- Development of the world mushroom industry: applied mushroom biology and international mushroom organizations (IJMM 2008;10;195-208)

- The role of culinary-medicinal mushrooms on human welfare with a pyramid model for human health (IJMM 2012;14(2):95-134)

- Current and future research trends in agricultural and biomedical applications of medicinal mushrooms and mushroom products (IJMM 2018;20(11):1034-1048)

In 2017, we published together with Professor S-T Chang a chapter in Oxford Research Encyclopedia of Environmental Science (Oxford University Press; doi: 10.1093/acrefore/9780199389414.013.231) dedicated to the cultivation and environmental impact of mushrooms. We highlight that in our time mushrooms can be used as food, tonics, medicines, as cosmeceuticals, and natural biocontrol agents in plant protection with insecticidal, fungicidal, bactericidal, herbicidal, nematodicidal, and antiphytoviral activities. The multidimensional nature of the global mushroom cultivation industry, its role in addressing critical issues faced by humankind, and its positive contributions are presented in this chapter. Furthermore, mushrooms can serve as agents for promoting equitable economic growth in society. Since lignocellulosic wastes are available in every corner of the world, they can be properly used in the cultivation of mushrooms, and therefore could pilot a so-called white agricultural revolution in less developed countries and in the world at large. Mushrooms demonstrate a great impact on agriculture and the environment and also have great potential for generating a great socioeconomic impact in human welfare on local, national, and global levels.

Professor Chang, with his ability to learn languages and his ease in adapting to various cultures, currently lives in Canberra, Australia, with his family. He is married to Judy Li-Ju Chang (née Lee), and their children are David Ming-Tsan, Barbara Ming-Wai, Judy Ming-Sze, Ernest Ming-Cheng, and Jennifer Ming-Jing. Professor Chang and his wife have 14 grandchildren and 3 great-grandchildren. His avocations are traveling, reading, golf, cycling, and walking. From the first encounter with him, you sense the warmth of his personality, and his outgoing, unconventional nature. He is an extraordinary, vibrant man in the broadest sense of the word. People are attracted to him like a magnet because of his charm, wit, and erudition. Chang's wide circle of interests, his clarity of scientific vision, his enormous energy, and his enthusiasm and honesty are just a few of his many great personal attributes.

Volume 22, Issue 9, 2020 
Chang is not only a creative and gifted scientist, but also an intellectual with a broad education. He celebrates his $90^{\text {th }}$ birthday at the peak of his creative activity. We-friends, colleagues, collaborators, and students - wish him good health, happiness in all his activities, new creative achievements, good fortune, and wisdom. 